\title{
Ulanowicz's Process Ecology, Duality and Emergent Deism
}

\author{
Robert K. Logan \\ Physics Department, University of Toronto, Toronto, Canada \\ Email: logan@physics.utoronto.ca \\ Received February $9^{\text {th }}, 2013$; revised March $10^{\text {th }}, 2013$; accepted March $17^{\text {th }}, 2013$
}

Copyright $(C) 2013$ Robet K. Logan. This is an open access article distributed under the Creative Commons Attribution License, which permits unrestricted use, distribution, and reproduction in any medium, provided the original work is properly cited.

\begin{abstract}
The different forms of duality in Robert Ulanowicz's (2009) book A Third Window are compared to the notion of neo-duality found in Logan and Schumann (2005). The influence of Heraclitus on the formulation Ulanowicz' duality is described. It is argued that the origin of language, which led to conceptualization and emotional intelligence, also gave rise to human spirituality, cooperation and altruism all of which contributed to human survival. The four mysteries of the existence of 1) matter/energy, 2) life, 3) human intelligence, and 4) human spirituality are identified. It is suggested that physics and chemistry deal with mystery number one; that Ulanowicz's process ecology describes mystery number two and the relation of life to energy/matter. Mystery number three entails process ecology and consideration of the effects of language. The emergence of the fourth mystery of spirituality and/or a belief in God is shown to have emerged from two uniquely human attributes, namely the abstract form of language-based intelligence and altruism. It is suggested rather than as an agent that influences events in the universe God, an idea that arises in the minds of humankind as a metaphor of all that is good in humankind.
\end{abstract}

Keywords: Newton; Darwin; Ulanowicz; Altruism; Spirituality; God; Language; Mind; Duality; Emergence

\section{Introduction}

I am neither a theist nor an atheist nor am I agnostic, I believe in the essential goodness, sacredness and spirituality of humanity and that forms my idea of God.

Ulanowicz's (2009) book, A Third Window, surveys the evolution of modern science from Newton's mechanics revolution, the first window, through Darwin's Origin of the Species, the second window to today's theories of chaos, complexity and emergence with his own additional twist of process ecology, the role of aleatorics (or chance), self-reference and the importance of a system's history, the third window. Not only does he underscore the importance of understanding the history of living systems but he also provides us with a history of science itself from the thinking of the Pre-Socratic philosophers through Newton, Carnot, Darwin, and quantum mechanics to the latest ideas in ecology, systems theory, cybernetics, complexity theory and information science.

His book has literally and figuratively opened up many new windows of thought for me giving rise to new insights, which I will report in this essay. His book has also caused me to rethink and reinterpret some of my earlier work on the origin of language (Logan, 2007), media ecology (Logan, 2010, 2013a), neo-duality (Logan \& Schumann, 2005; Logan, 2006), and the nature of information (Kauffman, Logan et al., 2007; Logan, 2013b). I will attempt to link up my earlier work with the ideas I encountered in Ulanowicz's fascinating and stimulating book with its emphasis on process rather than law and systems thinking rather than atomism. Ulanowicz has not only impacted my thinking about science but also about things transcendental and spiritual allowing me to formulate a notion of Emergent Deism in which I believe that the idea of God and spirituality arose from that which is good and altruistic about humankind.

One of the interesting features of Ulanowicz's (2009) approach, which I particularly enjoyed, perhaps because it parallels my own thinking, was his embrace of dualism or dialecticism (ibid.: pp. 7, 12 \& 92-93). Throughout his book, he identifies contrasting dualities often associated with the views of the first and third windows. In the preface he (ibid.: p. xxii) makes a distinction between mechanical and ecological ways of modeling nature indicating the superiority of the latter approach. At the very beginning of his Introduction he (ibid.: p. 2) refers to the C. P. Snow's Two Cultures of those who believe and those who do not believe that science will provide the solutions to the problems facing humankind (ibid.: p. 2). He (ibid.: pp. 2-3) then introduces us to Bateson's dualistic division of nature into "pleroma, those entities that are homogeneous, continuous and governed by matter and energy-the normal 'stuff' of science" and 'creatura'- cliving systems and similar physical analogs that were characterized more by individual differences (information) and reflexive actions". He then reports and argues for Bateson's notion that "ecology was not merely a derivative science, one wholly dependent on physics and chemistry. Rather...ecology afforded a truly different way of perceiving reality". So here we have a dialectic within science. An important distinction is made between the reductive sciences of physics and chemistry, as seen through the first window, and ecology coupled with complexity theory, emergence, and autocatalysis, as seen through the third window. Darwin's evolutionary theory, the second window in this scheme contributes to the transition from the first to the third window by introducing history into the 
description of the evolutionary process but it does not make it to the third window because Darwin's notion of natural selection operated with "Newtonian regularity, linearity and gradualism (ibid.: p. 36)" and did not incorporate chance, a key ingredient for the view from the third window.

Another dualistic element in A Third Window is the division of the universe into systems and processes versus laws and material things or particles [billiard balls (ibid.: pp. 22-23) as Ulanowicz calls them metaphorically], i.e. systems thinking versus atomism and processes versus laws. Also Ulanowicz created a duality between the nodes and linkages or flows of a networked universe (ibid.: p. 9). The sum of all these forms of duality either identified by Ulanowicz or formulated by him I chose to denote as Ulanowicz duality.

Ulanowicz makes an extremely important distinction between his form of process duality and Cartesian duality likening his form of duality to the thinking of Heraclitus and Hegel.

Yet one other important change in thinking is demanded by process ecology: recognition that development is the outcome of dual and opposing tendencies...Patterns and forms in the living realm result from transactions between agonistic tendencies. Processes that build organized activities are continually being eroded by dissipative losses. While these tendencies oppose one another in the near field, they are seen to be mutually obligatory under a wider vision (ibid.: p. 118).

We can also formulate Ulanowicz duality as chance and necessity duality or law and process duality where law is Newtonian-like and process is emergent-like, autocatalytic-like or cybernetic-like (involving both feed forward and feed back). Newtonian-like law entails efficient cause and is bottom up whereas emergent processes entail final cause and are top down. So we also have the duality of bottom up and top down causality. Perhaps a table is called for. Let us call it the Table of First and Third Window Dualities.

\section{Logan-Schumann Neo-Duality}

One of the reasons that Ulanowicz's dualistic/dialectical approach resonates with me is that it parallels some earlier work of mine in collaboration with John Schumann. In a paper published in Semiotica Logan and Schumann (2005) introduced the notion of neo-duality. We combined Schumann's (2003) notion of the Symbolosphere, the non-physical world of symbolic relationships which includes language and the human mind with Logan's (2000 \& 2007) Extended Mind model in which the mind and the brain are distinguished as different entities, which in itself entails a form of dualism. The mind emerges as distinct from the brain with the emergence of verbal language. Within our neo-duality framework we formulated a dialectic distinction between the symbolosphere, which includes the human mind and all its thoughts and communication processes such as language, on the one hand, and the physiosphere, on the other, which is simply the physical world of both abiotic and biotic matter and hence includes the human brain, which is carefully distinguished from the mind.

\section{First Window}

Mechanical models
Third Window

Ecological models (xxii, 3)

\begin{tabular}{|c|c|}
\hline $\begin{array}{l}\text { Science culture ala } \\
\text { C. P. Snow }\end{array}$ & $\begin{array}{l}\text { Humanistic culture ala } \\
\text { C. P. Snow (2) }\end{array}$ \\
\hline Pleroma ala Bateson & Creatura ala Bateson (3) \\
\hline $\begin{array}{l}\text { Reductive science of physics } \\
\text { and chemistry }\end{array}$ & $\begin{array}{l}\text { Constructive science of } \\
\text { ecology and complexity (4) }\end{array}$ \\
\hline Time reversal & $\begin{array}{l}\text { History_time has a } \\
\text { direction }(25,33)\end{array}$ \\
\hline Newtonian mechanics & $\begin{array}{l}\text { Entropy and Carnot's } \\
\text { Second Law of } \\
\text { Thermodynamics (34) }\end{array}$ \\
\hline Things, particles (billiard balls) & Processes (22) \\
\hline Atomism & Systems (22) \\
\hline Nodes & Links or flows (9) \\
\hline Laws-deterministic-predictable & $\begin{array}{l}\text { Processes that are emergent, } \\
\text { Non-deterministic and not } \\
\text { Predictable }(4,23,29)\end{array}$ \\
\hline Universal Laws of Physics & $\begin{array}{l}\text { No universal laws for } \\
\text { Biology (50) }\end{array}$ \\
\hline Forces & Propensities (55) \\
\hline Bottom Up Causality & Top Down Causality $(x, 5)$ \\
\hline Efficient Cause & Final Cause (19-20) \\
\hline Objects create processes & Processes create objects ( 75$)$ \\
\hline Homogeneity & Heterogeneiry (48-50) \\
\hline Algorithms & Dialectics (92) \\
\hline Overhead & Ascendency (89) \\
\hline Bottom Up Causality & Top Down Causality $(\mathrm{x}, 5)$ \\
\hline
\end{tabular}

Table of First and Third Window Dualities (page numbers in parentheses refer to page location in Ulanowicz's $A$ Third Window).

\section{Logan-Schumann Neo-Duality}

One of the reasons that Ulanowicz's dualistic/dialectical approach resonates with me is that it parallels some earlier work of mine in collaboration with John Schumann. In a paper published in Semiotica Logan and Schumann (2005) introduced the notion of neo-duality. We combined Schumann's (2003) notion of the Symbolosphere, the non-physical world of symbolic relationships which includes language and the human mind with Logan's (2000 \& 2007) Extended Mind model in which the mind and the brain are distinguished as different entities, which in itself entails a form of dualism. The mind emerges as distinct from the brain with the emergence of verbal language. Within our neo-duality framework we formulated a dialectic distinction between the symbolosphere, which includes the human mind and all its thoughts and communication processes such as language, on the one hand, and the physiosphere, on the other, which is simply the physical world of both abiotic and biotic matter and hence includes the human brain, which is carefully distinguished from the mind.

\section{The Extended Mind Hypothesis}

Logan (2007) in the Extended Mind Model proposed that 
before hominids acquired verbal language that the brain was basically a percept processor. With the emergence of verbal language the brain bifurcated into the brain plus the mind capable of conceptualization. It was with this development that fully human Homo sapiens emerged as a species distinct from their hominid ancestors.

What developments in hominid evolution gave rise to the complexity, the information overload, and, hence, the chaos that led to the bifurcation from perception to conception - and the emergence of speech. No single development or breakthrough triggered this event but rather the accumulation of developments that included the use of tools, the control of fire, the larger social settings fire engendered, the social organization required for large group living, food sharing, group foraging and co-ordinated large scale hunting that resulted from the larger living groups and the emergence of non-verbal mimetic communication as has been described by Merlin Donald (1991) in The Making of the Modern Mind...

One thing is clear, however, percepts no longer had the richness or the variety with which to represent and model hominid experience once the new skills of hominids like tool making and social organization were acquired. It was in this climate that speech emerged and the transition or bifurcation from perceptual thinking to conceptual thinking occurred. The initial concepts were, in fact, the very first words of spoken language. Each word served as a metaphor and strange attractor uniting all of the pre-existing percepts associated with that word in terms of a single word and, hence, a single concept. All of one's experiences and perceptions of water, the water we drink, bathe with, cook with, swim in, that falls as rain, that melts from snow, were all captured with a single word, water, which also represents the simple concept of water (Logan, 2007: p. 49).

The emergence of verbal language that made us human led to social intelligence or perhaps vice-versa social intelligence led to verbal language; actually most likely a combination of the two. One could even invoke Ulanowicz centripetality as a way of explaining the emergence of language. The important thing is that verbal language, social organization and co-operation reinforced each other and arose as emergent phenomena. The creation of new forms of co-ordination and social cohesion met the infinite variety of challenges life presented including the navigation through different forms of social conflict, the variety of which is endless.

The connection between language and social organization and intelligence is also made by Merlin Donald (1991) and Terrence Deacon (2007). Donald who regarded mimesis as the pre-adaptation for the generative grammar of spoken language connects mimesis with the creation of new social structures, which led in time to human altruism.

Mimetic skill represented a new level of cultural development, because it led to a variety of important new social structures, including a collectively held model of the society itself. It provided a new vehicle for social control and coordination, as well as the cognitive underpinnings of pedagogical skill and cultural innovation. In the brain of the individual, mimesis was partly the product of a new system of self-representation and mostly the product of a supramodular mimetic controller in which self-action may be employed to 'model' perceptual event representations. Many of the cognitive features usually identified exclusively with language were already present in mimesis: for instance, intentional communication, recursion, and differentiation of reference (Donald, 1991: pp. 199-200).

Deacon (2007) makes a similar connection between language and human social development by linking symbolic communication and social dynamics. He wrote,

The near synchrony in human prehistory of the first increase in brain size, the first appearance of stone tools for hunting and butchery, and a considerable reduction in sexual dimorphism is not a coincidence. These changes are interdependent. All are symptoms of a fundamental restructuring of hominid adaptation, which resulted in a significant change in feeding ecology, a radical change in social structure, and an unprecedented, (indeed, revolutionary) change in representational abilities. The very first symbol ever thought, or acted out, or uttered on the face of the earth grew out of this socio-economic dilemma, and so they might not have been very much like speech...Marriage is not the same as mating, and not the same as a pair bond. Unlike what is found in the animal world, it is a symbolic relationship....Symbolic culture was a response to a reproductive problem that only symbols could solve: the imperative of representing a social contract...The symbol construction that occurs in these ceremonies is not just a matter of demonstrating certain symbolic relationships, but actually involves the use of the individuals and actions as symbol tokens (ibid.: 400-1 \& 406).

To conclude, there is ample evidence from Donald (1991), Deacon (2007) and Logan (2007) to suggest that verbal symbolic language led directly to human co-operation, altruism and spirituality and these uniquely human qualities are products of our minds.

Contrary to a commonly held notion that the brain and the mind are the same, neo-duality entails the notion that the brain and the mind are distinct and that they belong respectively to the physiosphere and the symbolosphere (Logan \& Schumann, 2005). The physiosphere in a certain sense corresponds to Descarte's Res Extensa and the symbolosphere corresponds roughly to Descarte's Res Cogitans. No distinction is made between substance and property dualism, hence we characterized our form of duality as neo-duality. In our original paper we (ibid.) suggested that our neo-dualistic approach was justified on the basis that at our current understanding of neuroscience is unable to connect the functions of the mind with the actions of the brain and hence it makes sense from a practical point of view to distinguish between these two levels of phenomena. However in light of Ulanowicz's $A$ Third Window I would now argue that the brain is a thing, quite a complex thing but a thing nevertheless and the mind is a process. I would also argue that the mind is basically an emergent phenomenon possessing properties not possessed by its two main components, namely the brain and verbal language.

Building on Ulanowicz duality the physiosphere defined within the context of Logan-Schumann neo-dualism can be further subdivided or dualized by making a distinction as does Ulanowicz, Deacon (2012) and Kauffman (2010) of abiotic matter and the biosphere. The abiotic or material sphere of particles 
and their forces are governed by laws whereas the biosphere is governed by processes as Ulanowicz has pointed out.

\section{The Heraclitean versus the Parmenidean or Eleatic Point of View}

Just as work in biology can be categorized as investigations into either biotic form or function, studies of the surrounding physical world focus either on content or on flow. These dualities reflect the ancient dialectic between the Eleatic and Heraclitean schools of Greek philosophy, which continues to influence science today (mostly through its emphasis on the former perspective). Of course, it is no mystery why contemporary biology emphasizes form and content over function and flow-the former are much easier to quantify (Ulanowicz, 1991).

One of the key influences of Ulanowicz's process ecology is Heraclitus' notions of flux, perpetual change and strife as exemplified by the oft quoted metaphor of the river representing change and the notion that all is in flux. There are a number of versions of the quote that incorporates the river as a metaphor of change. The Sanford Encyclopedia of Philosophy claims this to be the closest to the original based on the agreement of several scholars:

On those stepping into rivers staying the same other and other waters flow. (B12)

Other versions include:

Ever-newer waters flow on those who step into the same rivers.

We both step and do not step in the same rivers. We are and are not.

No man ever steps in the same river twice.

The notion of constant change and flux as process is also contained in the following Heraclitean fragments:

This world-order [kosmos], the same of all, no god nor man did create, but it ever was and is and will be: everliving fire, kindling in measures and being quenched in measures. (B30)

We must recognize that war is common, strife is justice, and all things happen according to strife and necessity. (B80)

War is father of all and king of all; and some he manifested as gods, some as men; some he made slaves, some free. (B53)

Opposing the Heraclitean embrace of change and constant flux was Parmenides of the Eleatic School who argued that nothing changes suggesting if something changed from A to B then A would not be but non-being cannot be. He further maintained that nothing could come into being but always was and nothing could be extinguished but always will be unchanging because non-being cannot be. Parmenides was perhaps the first or one of the first thinkers to make use of deductive logic when he argued that being cannot be as is the case in the following fragments:

It is necessary to speak and to think what is; for being is, but nothing is not. (B 6.1-2)

How could what is perish? How could it have come to be? For if it came into being, it is not; nor is it if ever it is going to be. Thus coming into being is extinguished, and destruction unknown. (B 8.20-22)

[What exists] is now, all at once, one and continuous...Nor is it divisible, since it is all alike; nor is there any more or less of it in one place which might prevent it from holding together, but all is full of what is. (B 8.5-6, 8.22-24)

It is in this fragment that Parmenides argues for the power and self consistency of logic, which he denotes as logos:

For this view, that That Which Is Not exists, can never predominate. You must debar your thought from this way of search, nor let ordinary experience in its variety force you along this way, (namely, that of allowing) the eye, sightless as it is, and the ear, full of sound, and the tongue, to rule; but (you must) judge by means of the Reason (Logos) the much-contested proof which is expounded by me. (B 7.1-8.2)

The conflict between Heraclitus and Parmenides repeats itself in the conflicting view of the physicalist and the advocates of strong emergence as the Ulanowicz quote, which begins this section, proclaims. The physicalists or the reductionist monists argue that all reality including abiotic, biotic, mental and spiritual phenomena can be explained in terms of the basic laws of physics. The strong emergentists like Maturana, Varela, Kauffman, Deacon and Ulanowicz (and if I may include myself in this august group of thinkers) argue that biology cannot be reduced to physics and that self organization and processes are the key to understanding the biotic domain. For the physicalists nothing new emerges in this universe of ours in the sense that everything can be reduced to the four basic forces of nature, namely gravity, electromagnetism, the nuclear or strong force and the weak force. For the emergentists new phenomena arise as the components of a complex systems self-organize giving rise to properties not possessed by those components. Ulanowicz is quite explicit about making use of arguments developed by Elasser (1969 \& 1981) that rogue or complex chance play a role in the processes of the universe as is the case with the origin and evolution of life. "The operation of any system is vulnerable to disruption by chance events (Ulanowicz, 2009: p. 47).

Change is ever pervasive to anyone who observes the processes of nature. There are those that can go with the flow and enjoy the process and challenge of some thing new and those that find change upsetting and need something that does not change. Heraclitus embraced change and Parmenides of the Eleatic School rejected it. Emergentists embrace change, process and complexity and physicalists/monists are uncomfortable with them.

The challenge of science and philosophy is to explain the world of change with universal laws that did not change. Heraclitus took up this challenge by embracing change but suggesting that this change was, nevertheless, ruled by Logos. The word logos, which originated with the Greeks, is derived from the Greek verb legō $(\lambda \dot{\varepsilon} \gamma \omega)$ and had the common meaning of word, tale or speech. It was first used in philosophical discourse by Heraclitus, where it took on the extra metaphorical meanings of reason, rationality, measure and ruling principal based on the 
context in which he used the term as these fragments of his demonstrate:

This LOGOS holds always but humans always prove unable to understand it, both before hearing it and when they have first heard it. For though all things come to be in accordance with this LOGOS, humans are like the inexperienced when they experience such words and deeds as I set out, distinguishing each in accordance with its nature and saying how it is. But other people fail to notice what they do when awake, just as they forget what they do while asleep. - Diels-Kranz, 22B1

For this reason it is necessary to follow what is common. But although the LOGOS is common, most people live as if they had their own private understanding. - Diels-Kranz, 22B2

Listening not to me but to the LOGOS it is wise to agree that all things are one. -Diels-Kranz, 22B50 (Translations from Richard D. McKirahan, Philosophy before Socrates, Hackett, 1994.)

\section{The Four Mysteries}

In my Poetry of Physics course, which I have taught to humanities students at the University of Toronto since 1971, in order to make the students aware of what physics can and cannot describe, I identify for them what I consider to be the four basic mysteries of our universe, namely the phenomena and existence of

1) matter/energy, the domain of physics and chemistry;

2) life, the domain of biology and ecology;

3) mentality/intelligence, the domain of cognitive science and neuroscience; and

4) spirituality, the domain of philosophy and theology

Reductive physics and chemistry deals with mystery number one, matter and energy. Ulanowicz deals beautifully with mystery number two, life and ecology in A Third Window, carefully showing what distinguishes mysteries one and two from each other and at the same time showing how they are related. He deals with a certain aspect of mystery number three, intelligence or cognition in the sense that intelligence and cognition are closely associated with living systems in the sense that even the simplest organism must respond correctly to resources such as energy or nutrients by finding and acquiring them and to toxins by avoiding them. A description of intelligence, an essential part of life, however, requires another level of explanation above and beyond that of an explanation of life especially as it concerns human intelligence. This is not an area that Ulanowicz has dealt with in A Third Window. I believe that the consideration of the origin of language, media ecology and Logan-Schumann neo-duality developed above within the context and framework of Ulanowicz's treatment of life and ecology provides a richer picture of intelligence and cognition and complements his achievement.

\section{The Fourth Mystery-Spirituality and Things Transcendental}

Not every aspect of human behaviour, however can be explained in terms of physics, biology and cognition. There is another dimension to human existence that cannot be explained only in terms of intelligence and that pertains to human altruism, morality and spirituality and even to the transcendental categories such of the sacred, the soul and God.

This area is not in the domain of science, which as a disci- pline is agnostic with respect to things spiritual and/or transcendental. There are even a significant number of scientists, usually reductionists and monists, that are hostile to and even deny the existence of anything spiritual or transcendental. And those that are agnostic with respect to these putative phenomena would still claim that any explanation of this realm is totally outside of the purview of scientific consideration. Given Popper's criteria of the need for a proposition to be falsified if it is to be considered a scientific proposition I have to agree any discussion of spiritual matters cannot be construed as science.

Nevertheless stimulated by my reading of $A$ Third Window I would like to attempt to offer a naturalistic philosophical explanation for the emergence of human altruism and spirituality as well as the universal inclusion in all human cultures of some form of transcendentalism and the notion of a deity or deities.

\section{God as a Metaphor of All That Is Good in Humankind}

The following thoughts might prove offensive to traditional believers in orthodox religion that envisage a God living in heaven and watching over each and every one of us. My idea of God is quite different and is consistent with my understanding of modern science. I am respectful of the religious beliefs of others and the purpose of these reflections is not to criticize the religious thinking of others but to argue that one can be both secular and spiritual at the same time. My spirituality and my understanding of God reflect the Jewish values of my upbringing. I do not accept the stories of Hebrew Scripture as literal but they have real meaning for me metaphorically as do many of my religious traditions that I pick and chose to observe because they make sense to me. I do not attend synagogue regularly but I am moved when I do, as I am in the holy houses of other religions. My family due to intermarriage celebrates both Jewish and Christian holidays.

I believe in God but I do not believe that there exists a God that controls every event in the universe. To my way of thinking how could such a Being if He or She existed, allow such things as the Shoah (the Jewish Holocaust) or the senseless acts of violence, ethnic cleansings, murders, tortures that occur far too often perpetrated by those among us who have lost their sense of humanity and are totally depraved. I still take comfort in and believe in the goodness of humankind despite the existence of evil people who commit such atrocities. These people who do evil are a small minority of humankind. I believe in the intrinsic goodness of humankind and that forms my belief in God.

Spirituality and/or a belief in God requires two attributes that are unique to humans, namely an abstract form of languagebased intelligence and an altruistic spirit of loving and caring for others as the final cause that motivates one's actions. The altruistic values that motivates human behaviour is often but not always formulated in terms of a Deity. Many believe that altruism is derived from God. I believe that human altruism that emerged in the speciation from our hominid ancestors to Homo sapiens is the source of our notion of God. God is a symbol, an example, of how we believe humans should behave. God and transcendence is a way of describing the complexity of human altruism. God is a metaphor that represents all that is good within the human sphere.

For me God exists in the minds of humans; but not as a king sitting on a throne in heaven surrounded by cherubim. God 
exists in the millions of acts of kindness and sacrifice humans make to benefit their fellow humans. God is charitable acts, kindness, love, caring, and giving to others both materially and spiritually. For me God arises or emerges as the result of the final cause of those that act in the service of others. God's nemeses, the devil or devils, are those humans who through their selfish behaviour exploit and/or harm others. Those that cheat six days a week and go to their respective house of worship on the seventh day have no real notion of God and are devoid of decent values. They are hypocrites and they are the real devils not the ones that some believe dwell in Hell. Atheists who deny the existence of God are in denial of how values and caring defines us as humans. It is those humanistic values and caring that is the focus and source of our belief in God, which is backed up by action, service and good deeds. Some atheists are in denial because they take the formulations of God literally. Many are often angry because of the many instances they observe where people take advantage of others using God and religion as a cover to exploit them

I do not believe that God created the universe as we know it but rather it emerged by chance. It is a matter of chance that our universe is composed of matter and not antimatter according to our understanding of how our universe arose out of the Big Bang 15 billion years ago. Perhaps there is another parallel universe of antimatter or, even as some cosmologists speculate, an infinite number of universes. For me this universe is paradise enough and we should try to get it right. Perhaps the matter and antimatter universes had to separate just as Isaac and Ishmael were separated in Scriptures. It was by chance that more matter was created than antimatter and it was also by chance that life emerged and it was by chance that human life emerged with the gift of speech and conceptualization, and as a conesquence the ability to conceive, to care, to love, to be spiritual, and to be altruistic. It was in this way that human life created the notion of God. I do not believe it was the other way around as it is told in Scriptures that God created us and placed us in the Garden of Eden. I believe, we humans that arose by chance, created God or gods as a metaphor for that altruistic spirit that arose in us by chance and in all likelihood caused us to thrive through communal autocatalysis and grow as the community of humankind. In other words the idea of God arose from humans as a way of expressing their spiritual and altruistic nature, which served as a survival tool for humanity.

I therefore would conclude that God did not create us in his image rather we created God in our image, the image of what is best in us as humans - our image of the saintly, the altruistic, the charitable, the kind and those who are considerate of there fellow humans. God is an example of how humans should behave: caring, forgiving, loving, and slow to anger. God has the qualities that a good parent should possess. Perhaps this why we call God, Father.

Perhaps this also explains why God or the gods are represented as humans as is the case in so many traditions. Jesus was human; Krishna was human; the Buddha was human; Zoroaster was human. Lao Tzu and Confucius were human. In China and certain other cultures one worships one's ancestors. The gods of polytheistic religions such as that of the Greeks and the Romans were basically human possessing both that which was inspiring but also in possession of many of the foibles of humans.

To sum up I believe my theology might be described as Emergent Deism - God is not nature but God arises out of hu- man nature. Having acknowledged the contribution of my religious traditions I must also acknowledge that my formulation of my religious views here were influenced by three books written by scientists. They are in the order in which I read them: Stuart Kauffman's Reinventing The Sacred, Terrence Deacon's Incomplete Nature and Robert Ulanowicz's A Third Window. Paradoxically, I was also influenced by a highly religious person, namely, Marshall McLuhan with whom I frequently attended Catholic Mass at lunchtime. He prayed for his salvation and I prayed to understand what we had discussed that morning. We had a special bond despite our different ways of understanding spirituality. When we wrote a paper entitled Alphabet Mother of Invention (McLuhan \& Logan, 1977) in which we linked together alphabet, codified law, science, deductive logic and monotheism McLuhan had no trouble with my suggestion that the idea of monotheism arose among the Hebrews. I do not think he would have a problem with my unorthodox interpretation of how the idea of God arose. If it helps atheists see the importance of and accept spirituality then it should be acceptable to theists who naturally will see things differently than me.

While I am on the topic of prayer let me share my thoughts about its efficacy. Although I do not believe in the agency of God I do believe that prayers work. I believe it is the power of self fulfilling prophesy that makes prayer effective. The term "self-fulfilling prophecy" was coined in 1948 by Robert K. Merton, who drew upon W. I. Thomas's (Thomas \& Thomas, 1928: pp. 571-72) well-known dictum: "if men define situations as real, they are real in their consequences"

Given the environmental crisis with global warming that the human community is facing it is imperative that a common ground of spirituality is created among the secularists especially those that are scientists and the community of believers. Whether one formulates their spirituality in a traditional way or in an unorthodox way we must find a common cause and learn how to work together. The resolution of the challenge we face cannot be achieved by science alone. It will require a spiritual dimension as well. There is no guarantee that this precious moment in the history of the cosmos in this small corner of the universe that allowed human culture to thrive will long endure. We have become so powerful with our technologies that we risk destroying the conditions that make our existence possible. What I find so dangerous about the monist reductionist position is the hubris that science can solve any problem that we create. The book Collapse by Jared Diamond (2007) documents how societies in the past collapsed through hubris. A danger exists on the other side as well among the traditionalists in the religious community who believe that God would not allow the collapse of the conditions for human life on the planet. I remind those skeptics of three things. First, that God helps those who help themselves. Second, in both the Christian and Jewish traditions the end of days is spoken of. And third as is related in Scriptures God had no problem flooding the planet once before. Who will be today's Noah if global warming melts the ice caps and floods the planet once again.

\section{REFERENCES}

Deacon, T. (2012). Incomplete nature: How mind emerged from matter. New York: Norton.

Diamond, J. (2007). Collapse: How societies choose to fail or succeed.

New York: Penguin Books.

Elasser, W. M. (1969). A causal phenomena in physics and biology: A 


\section{R. K. LOGAN}

case for reconstruction. American Scientist, 57, 502-516.

Elasser, W. M. (1981). A form of logic suited for biology. In R. Rosen (Ed.), Progress in theoretical biology (pp. 23-62). New York: Academic Press.

Kauffman, S. (2010). Reinventing the sacred: A new view of science. New York: Basic Books.

Logan, R. K. (2000). The extended mind: understanding language and thought in terms of complexity and chaos theory. In L. Strate (Ed.), 2000 Communication and speech annual (pp. 63-80). New York: The New York State Communication Association.

Logan, R. K. (2006). Neo-dualism and the bifurcation of the symbolosphere into the mediasphere and the human mind. Semiotica, 160, 229-242.

Logan, R. K. (2007). The extended mind: the emergence of language, the human mind and culture. Toronto: University of Toronto Press.

Logan, R. K. (2010). Understanding new media: Extending Marshall McLuhan. New York: Peter Lang Publishing.

Logan, R. K. (2013a forthcoming). McLuhan misunderstood: Setting the record straight. Toronto: The Key Publishing House.

Logan, R. K. (2013b forthcoming). What is information? Toronto: DEMO Publishing. doi:10.1515/semi.2005.2005.155.1part4.201

Logan, R. K., \& Schumann, J. (2005). The symbolosphere, conceptualization, language and neo-dualism. Semiotica, 155, 201-214.

McLuhan, M., \& Logan, R. K. (1977). Alphabet, mother of invention. Et Cetera, 34, 373-383.

Merton, R. K. (1968). Ch. 3: The self-fulfilling prophecy. In Social theory and social structure (2nd ed.) (pp. 475-490). New York: Free Press.

Thomas, W. I., \& Thomas, D. S. (1928). The child in America: Behavior problems and programs. New York: Knopf.

Ulanowicz, R. E. (1991). The ecosystem structure of Lake Annie, Highlands County, Florida: Preliminary research needs. http://www.archbold-station.org/station/documents/publicationspdf/ Ulanowicz-1991-LkAnnie-visinvrep.pdf

Ulanowicz, R. E. (2009). A third window: Natural life beyond Newton and Darwin. West Conshohocken, PA: Templeton Foundation Press. 